Dokuz Eylül Üniversitesi-Mühendislik Fakültesi

Fen ve Mühendislik Dergisi

Cilt 20, Sayı 60, Eylül, 2018
Dokuz Eylul University-Faculty of Engineering Journal of Science and Engineering Volume 20, Issue 60, September, 2018

DOI: $10.21205 /$ deufmd. 2018206069

\title{
Yaş Üzümde Pestisit Kalıntılarının GC [Çoklu-Dedektörlere $(\mu$-ECD, MSD, Dual-FPD) sahip gaz kromatografisi] ile Çoklu Kalıntı Tayini için Analiz Yönteminin Geliştirilmesi
}

\section{Gözde TÜRKÖZ BAKIRCI ${ }^{* 1}$, Yaşar HIŞIL ${ }^{2}$}

${ }^{1}$ Dokuz Eylül Üniversitesi, Seferihisar F. Hepkon Uyg. Bil. Y.O, Gastronomi ve Mutfak Sanatları Bölümü, 35460, İzmir. (ORCID: 0000-0001-9910-3314)

2Ege Üniversitesi, Mühendislik Fakültesi, Gıda Mühendisliği Bölümü, 35100, İzmir.

(ORCID: 0000-0002-3652-5074)

(Alınış / Received: 14.02.2018, Kabul / Accepted: 10.04.2018, Online Yayınlanma / Published Online: 15.09.2018)

Anahtar Kelimeler

Üzüm,

GC/ECD/FPD/MSD,

Pestisit,

Çoklu kalıntı

analizi
Özet: Ülkemizde yaş üzümdeki pestisit kalıntılarının tayini için hızlı, ucuz, kolay, güvenli, etkili, kesin sonuç veren ekstraksiyon ve analiz yöntemi geliştirilmiştir. Geliștirilen metotta, örnekler basınç altında sıvı TFE çözgeni kullanılarak ekstrakte edilmektedir. Elde edilen ekstraktlar GC [Çoklu-Dedektörlere $(\mu$ ECD, MSD, Dual-FPD) sahip gaz kromatografisi] ile analiz edilmektedir. Bu metot, isomerleri ile birlikte 61 aktif maddenin GC [Çoklu-Dedektörlere( $\mu$-ECD, MSD, Dual-FPD) sahip gaz kromatografisi]'de doğrulama ve kantitatif analizine imkan vermektedir. Metot, geçerli kılınmış (valide edilmiş) ve sonuçlar kabul edilir aralıklarda bulunmuştur. Pestisitlerin gözlenebilme sınırı (LOD) ve tayin sınırı (LOQ), Maksimum Kalıntı Limitleri (MRL)'nden düşük, matrikste hazırlanan kalibrasyonlardan elde edilen korelasyon katsayıları (R2) 0.99'dan yüksek, geri kazanımlar \% 70-120 arasında ve relatif standart sapmaları (\% RSD, doğruluk ve tekrarlanabilirlik) \%20'den düşük bulunmuştur.

\section{Development of Multi Residue Analysis Method in Determining Pesticide Residues on Grapes Simultaneously by GC [Gas Chromatography Having Multi-Detector ( $\mu$-ECD, MSD, Dual-FPD)]}

Keywords
Grapes,
GC/ECD/FPD/MSD,
Pesticides,
Multi residue
analysis

Abstract: Determination of pesticide residues in fruits and vegetables for giving fast, cheap, easy, safe, effective, rugged results of the extraction and analysis methods have been developed. In developed method, the samples were extracted using pressurized fluid solvent (1,1,1,2-TFE) and extracts were analysed by GC [having multi-detector ( $\mu$-ECD, MSD, Dual-FPD)] with gas chromatography]. This method gives the chance for verifing and quantitation for together isomers of 61 active substance by using GC. Method was validated and the results were accepted in normal ranges. Limit of detection (LOD) and 
G.T. Bakırcı vd. / Yaş Üzümde Pestisit Kalıntılarının GC [Çoklu-Dedektörlere( $\mu$-ECD, MSD, Dual-FPD) sahip gaz kromatografisi] ile Çoklu Kalıntı Tayini için Analiz Yönteminin Geliştirilmesi

quantitation (LOQ) values of active substances were found lower than Maximum Residue Limits (MRL) and correlation coefficients (R2) were higher than 0.99 with matrix matched calibration and recoveries were found between 70-120\% and relative standart deviations were lower than $20 \%$ (RSD \%, for accuracy and repeatability).

*Sorumlu yazar: gozde.turkoz@deu.edu.tr

\section{Giriş}

Pestisitlerin kullanımı çok eski tarihlere dayanmaktadır. M.Ö. 1500'lere ait bir papirüs üzerinde bit, pire ve eşek arılarına karşı insektisitlerin hazırlanışına dair kayıtlar bulunmuştur. 19.yy'da zararlılara karşı inorganik pestisitler kullanılmış, 1940'lardan sonra pestisit üretiminde organik kimyadan faydalanılmıș, DDT ve diğer iyi bilinen insektisit ve herbisitler keşfedilmiştir. Pestisit kalıntılarının en önemli kaynağının gıdalar olması sebebi ile 1960 yılında FAO ve WHO tarafından "Pestisit Kalıntıları Kodeks Komitesi" kurulmuş ve bu komitenin çalışmaları sonucu konu ile ilgili tanımlamalar yapılmış, bilimsel araştırma verilerine dayanılarak gidalarda bulunmasina izin verilen maksimum kalıntı değerleri saptanmıştır [1].

Artan gida güvenliği talebi, böcek ilaçları ile kontamine olmuş gıda maddelerinin tüketimi ile ilgili risk konusunda hızlandırılmış çalışmalara neden olmuştur [2]. Son yllardaki çalışmalar, pestisitlerin yoğun kullanıldığını ve bu durumun çevre ve insanlar için kirlilik riskini arttırdığını göstermiştir [3].

İnsan sağlığını korumak amacı ile pestisit kalıntıları ve metabolitleri için, tebliğler ve yönetmelikler maksimum kalıntı seviyesini (MRL) belirlemektedir. Genel olarak, Avrupa Gida Yönetmeliklerinde $\quad(91 / 414 / E E C)$, MRL'ler $\quad 0.01-10 \quad \mathrm{mg} / \mathrm{kg}$ arası değişmektedir [4]. Bu farklılık, kullanım ve pestisit kombinasyonuna göre değișmektedir. Yönetmelikler Komisyon Direktiflerine $\quad(1999 / 50 / E C$ ve 1999/30/EU) uygun olarak, çocukların tüketimine yönelik gıdalar için daha düşük limitler içermektedirler. Buna göre, çocuk tüketimine yönelik gıdalardaki pestisit miktarı tespit edilemeyecek seviyede olmalıdır $[0.01$ $\mathrm{mg} / \mathrm{kg}$ ) [5].

Başta Avrupa Birliği ülkeleri olmak üzere gelişmiş olan ülkelerin hemen hemen hepsinde, tarımsal ürünlerin maksimum kalıntı limitlerine uyulup uyulmadığını kontrol ettikleri kalıntı izleme programları bulunmaktadır. Ülkemiz açısından da Avrupa Birliği'ne uyum aşamasında 2004 yılında Koruma ve Kontrol Genel Müdürlüğünce denetim ve izleme çalışmaları başlatılmıştır.

Meyve ve sebzelerdeki pestisit kalıntılarının sağlık üzerindeki olumsuz etkileri tüketiciler için problem teșkil etmektedir. Ham ve işlenmiş taze ürünlerde pestisitlerle karşılaşılmasının yanı sıra birçok çalışmada gıda işlem yöntemlerinin, sebze ve meyvelerde pestisitleri azalttığı saptanmıştır $[6,7,8,9,10]$.

Vitaceae ailesine ait olan üzüm (Vitis L.) dünyadaki en popüler ve en yaygın olarak üretilen meyvedir. Birleşmiş milletler gıda ve tarım örgütü (FAO) istatistiklerine göre, 2014 yllında üretilmiș olan 75 milyon ton küresel üzüm üretiminin \%17 si Çin'de, \%9.6 si Amerika'da, \%9.3 ü İtalya'da, \%8.3 ü İspanya'da, \%8.2 si Fransa'da ve \%5.6 si Türkiye'de üretilmiştir [11].

Bitki koruma ürünü (BKÜ) olarak tanımlanan pestisitler bilgili ve bilinçli kullanılmadığında, tavsiye dışı kullanıldığında, son ilaçlama ile hasat arasında bırakılması gereken süreye uyulmadığında, uygun ilaçlama aletleri 
G.T. Bakırcı vd. / Yaş Üzümde Pestisit Kalıntılarının GC [Çoklu-Dedektörlere( $\mu$-ECD, MSD, Dual-FPD) sahip gaz kromatografisi] ile Çoklu Kalıntı Tayini için Analiz Yönteminin Geliştirilmesi

kalibre edilmeden kullanıldığında, gerek olmadığı halde birden fazla ilaç karıștırılarak kullanıldığında, etiketlerinde belirtilen doz ve zamanda kullanılmadığında, ürünler üzerinde veya içinde kalıntı bırakabilmektedir [12].

Bugüne kadar 6000 kadar sentetik bileşik patent almasına karşın, bunlardan 600 kadarı ticari kullanım olanağı bulmuștur. Ülkemizde tarımı yapılan kültür bitkileri, sayıları 200 ü aşan hastalık ve zararlının tehdidi altında olup yeterli mücadele yapılmadığı için toplam ürünün yaklaşık 1/3' ü kayba uğramaktadır.

Günümüzde modern tarımda kimyasal mücadeleden tamamen vazgeçmek mümkün değildir. Ancak, tarımda kullanılan pestisitleri zamanında ve bilinçli uygulamak suretiyle olumsuz etkilerini minimuma indirmek mümkündür $[13,14]$.

Geçtiğimiz yıllarda tarım ürünleri ticaretinin dünya çapında artması ile uzmanlar, tarım ürünlerinde pestisit kalıntılarının analizi için yöntem çalışmalarına daha fazla önem vermeye başlamışlardır. Tarımsal üretim için gerekli olan pestisitler insektisit, fungusit, herbisit, büyüme düzenleyicileri gibi sinıfları içermektedirler. $\mathrm{Bu}$ anlamda, pestisitler geniș bir içerik yelpazesine sahiptirler ve kullanılan miktarlar her ülkenin farklı bölgelerinde değişmektedir. Tarım ürünlerinin kalitesini sağlamak için kullanılan pestisitlerin, ürünün üretiminden tüketimine kadar geçen her aşamada kontrol ve denetimlerinin yapılması gerekmekte ve kalıntıları eşzamanlı olarak tayin etmekte kullanılacak güvenilir, hızlı, ucuz ve verimli analitik yöntemlerin geliştirilmesi gerekmektedir. Ancak bu şartlar sağlandığında tüketicinin sağlığını güvence altına almak ve çevreyi korumak mümkün olacaktır.
Ayrıca pestisit kalıntı analizi, uluslar arası ticarette (ithalat, ihracat) ve kontrollerde önemli bir konuma sahiptir. $\mathrm{Bu}$ durum, yetkili laboratuarların doğru şekilde kontrolleri gerçekleştirmeleri amacı ile mümkün olduğunca etkili çoklu-kalıntı yöntemleri (MRMs) geliştirme gereksinimini beraberinde getirmektedir [15].

$\mathrm{Bu}$ çalıșmada, ülkemizde yaș üzümde kullanımı yasak olan ve kullanımı olan pestisitlerin kalıntı miktarlarının, GC [Çoklu-Dedektörlere ( $\mu$-ECD, MSD, DualFPD) Sahip Gaz Kromatografisi] ile eşzamanlı tayini için Hızlı, Ucuz, Kolay, Güvenli, Etkili, Kesin sonuç veren örnek hazırlama ve ekstraksiyon yöntemi oluşturulması amaçlanmıştır. Araștırmanın diğer amacı ise örnek ekstraktlarındaki pestisit kalıntılarının GC [Çoklu-Dedektörlere ( $\mu$-ECD, MSD, Dual-FPD) Sahip Gaz Kromatografisi] cihazlarında tanımlanması ve nicel analizinin yapılabilmesi için Çoklu Kalıntı Analiz Yönteminin geliştirilmesidir.

\section{Materyal ve Metot}

\subsection{Kullanılan Kimyasallar}

Çalışmada kullanılan pestisit standartları, Dr. Ehrenstorfer Türkiye temsilcisinden temin edilmiştir. Ekstraksiyon çalıșmalarında Dupont Suva 134a 1,1,1,2-TFE (tetrafluoroethane) çözücüsü ve Merck marka \%99,9 saflıkta toluen kullanılmıştır.

2.2 Araştırmada kullanılan örnekler Araştırmada ilaçlanmamış yaş üzüm örnekleri kullanılmıştır. Örnekler organik tarım üretimi yapan bazı firmalar ile hiç ilaçlanmadığından emin olunan üretim yerlerinden alınmıştır. Tüm örneklerin analizler neticesinde pestisit içermediği tespit edilmiştir. Her bir örnek en az $3 \mathrm{~kg}$ olacak şekilde toplanmış ve hemen homojenize 
G.T. Bakırcı vd. / Yaş Üzümde Pestisit Kalıntılarının GC [Çoklu-Dedektörlere( $\mu$-ECD, MSD, Dual-FPD) sahip gaz kromatografisi] ile Çoklu Kalıntı Tayini için Analiz Yönteminin Geliştirilmesi

edilerek analiz edilinceye kadar $-18^{\circ} \mathrm{C}$ konsantrasyonunda stok çözeltileri de derin dondurucuda saklanmıştır.

\subsection{Kullanılan cihazlar}

Homojenizatör:

Örneklerin parçalanması ve homojen bir şekilde dağılımın sağlanması amacı ile Waring Blender kullanılmıștır.

Terazi: Tartım işlemlerinde, SARTORIUS marka CP225D model $(0,00001 \mathrm{~g}$ hassasiyetli) ve ED323S-CW model $(0,01 \mathrm{~g}$ hassasiyetli) teraziler kullanılmıştır.

Tüp Karıștırıcısı: Ekstraksiyonda örneklerin TFE ve toluen ile karışımının sağlanması amacı ile HEIDOLPH REAX TOP 2000 kullanılmıștır.

3 Dedektörlü Gaz Kromatografisi: Otomatik Enjektörlü AGILENT marka 3 Dedektörlü GC (HP 6890 GC, $\mu$-ECD, Dual FPD, 5975 MSD) cihazı kullanılmıştır.

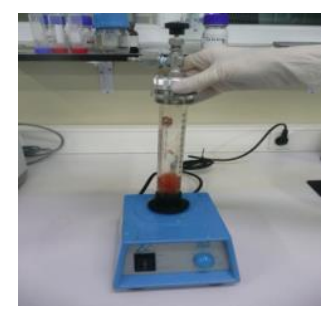

Şekil 1. Ekstraksiyon işleminde kullanılan tüp karıștırıcı

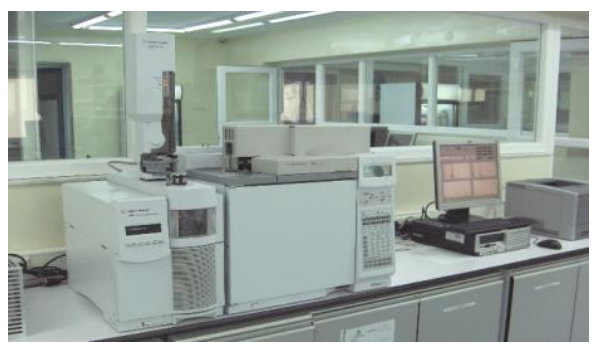

Şekil 2. Agilent 3 Dedektörlü GC (HP 6890 GC, $\mu$-ECD, Dual FPD, 5975 MSD) cihazı

\subsection{Standartların Hazırlanması}

$\mathrm{Bu}$ çalışmada kullanılan pestisit etkili maddelerinin, toluende $1 \mathrm{mg} / \mathrm{ml}$ hazırlanmıştır. Metotların ve cihaz koşullarının optimizasyonu için öncelikle pestisit etkili maddelerinin her biri ayrı ayrı cihazlara verilerek alıkonma zamanları tespit edilmiştir. 3 Dedektörlü GC (HP 6890 GC, $\mu$-ECD, Dual FPD, 5975 MSD) cihazı için aktif maddelerin kimyasal grupları ve alıkonma zamanları göz önünde bulundurularak 5 farklı karıșım hazırlanmıştır. Oluşturulan karışımlar ile cihaz parametreleri modifiye edilerek 7 farklı konsantrasyonda 7 noktalı kalibrasyon grafikleri çizilmiştir.

\subsection{Matriks etkisi}

Analizlerde matriksin etkisini ortaya koymak amacı ile kalibrasyon grafikleri matriks ile oluşturulmuştur. Pestisit kalıntısı içermeyen örneklerden elde edilen ekstrakt içerisine istenilen konsantrasyonda standart karışım ilave edilerek cihaza enjeksiyon yapılmıştır. 3 Dedektörlü GC (HP 6890 GC, $\mu$-ECD, Dual FPD, 5975 MSD) cihazı için 100$5000 \mathrm{ng} / \mathrm{ml}$ arasinda 7 farklı konsantrasyonda matriks etkili (matrix matched) kalibrasyon grafikleri oluşturulmuştur.

\subsection{Dedektörlü Gaz Kromatografisi cihazı şartları}

Otomatik Enjektörlü AGILENT marka 3 Dedektörlü GC (HP 6890 GC, $\mu$-ECD, Dual FPD, 5975 MSD) sisteminde bir enjeksiyonla örnekte bulunan pestisitler kolonda ayrıldıktan sonra kolon çıkışında bulunan üç-yollu özel ayırıcı (three-way splitter) yardımıyla üç ayrı dedektöre aynı anda gönderilmektedir. Belli alıkonma zamanına sahip bileşiğin üç dedektörden alınan sinyalleri aynı anda elde edilir. Bu sinyallerin karşılığı olan kromatogramlar bir arada değerlendirilerek kalitatif, kantitatif analiz gerçekleştirilir ve pikin kimliği teşhis edilir. 


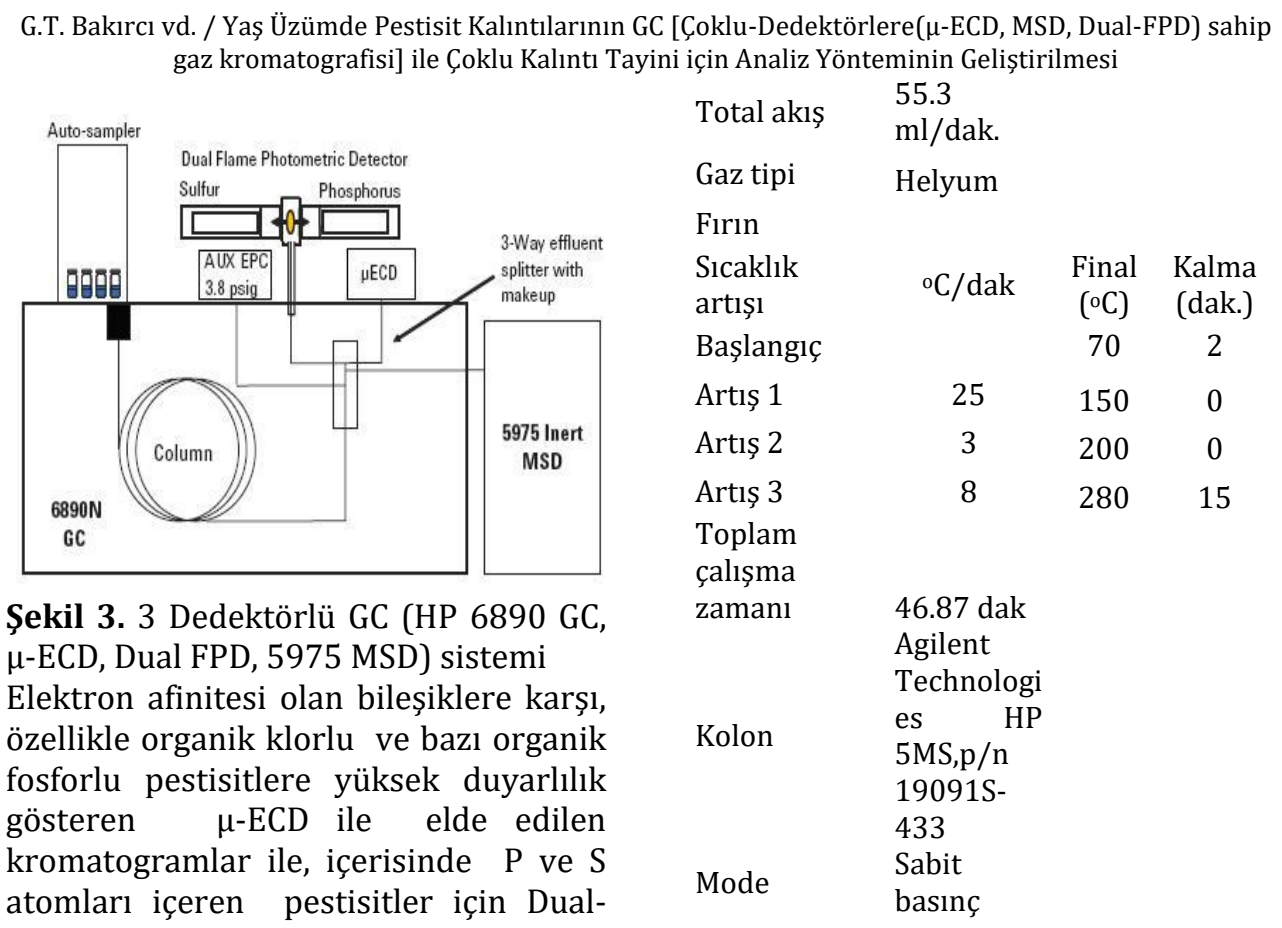

FPD ile elde edilen kromatogramlar kalitatif ve kantitatif analiz için uygundur. Ayrica aynı anda MSD den de hem tarama (SCAN) modunda, hem de seçilmiş iyon izleme (SIM) modunda alınan total iyon kromatogramları ile bileșiklerin kimlikleri belirlenebilmektedir. Böylece kalitatif ve kantitatif tayin kesin olarak yapilabilmektedir [16].

Tablo 1. Gaz kromatografisi, Kütle Dedektör, $\mu$-ECD, FPD ve Üç-Yollu Ayırıcı' nın çalışma parametreleri

\begin{tabular}{|c|c|}
\hline GC & Agilent $6890 \mathrm{~N}$ \\
\hline Giriş (İnlet) & EPC Split/Splitless \\
\hline $\begin{array}{l}\text { Enjeksiyon } \\
\text { Modu }\end{array}$ & $\begin{array}{l}\text { Splitless, } 1.0 \quad \mu \mathrm{l} \quad \text { (7683B } \\
\text { Autoinjector) }\end{array}$ \\
\hline Enj.Sıcaklığı & 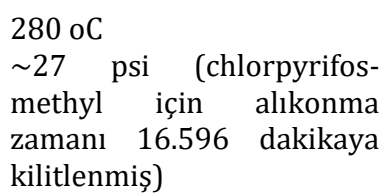 \\
\hline $\begin{array}{l}\text { Temizleme } \\
\text { gaz akışı } \\
\text { (purge flow) } \\
\text { Temizleme } \\
\text { zamanı } \\
\text { (purge time) }\end{array}$ & $50.0 \mathrm{ml} / \mathrm{dak}$. \\
\hline
\end{tabular}

\section{6 Örneklerin Ekstraksiyonu}

Örneklerin ekstraksiyonunda hızlı, ucuz, kolay, güvenli, etkili, kesin sonuç veren metot geliştirilmeye çalışılmış olup, ekstraksiyon denemelerinde basınç altında SIVl 1,1,1,2-TFE (tetrafluoroethane) çözgeni kullanılarak çalışmalar gerçekleştirilmiştir. Çalışmamızda kullanılan pestisitler toluen çözgeninde çözülmüştür. 1,1,1,2TFE (tetrafluoroethane) ve toluende birbiri içinde çözünmekte olup 1,1,1,2TFE (tetrafluoroethane) çözgeni ekstraksiyon sonrası buharlaşarak ayrılmakta ve kalıntı bırakmamaktadır. $10 \mathrm{~g}$ numune ekstraksiyon kabina tartılarak üzerine $1 \mathrm{ml}$ toluen ilave edilir. Sistem aparatları birleștirilerek vakum pompası çalıştırılır ve ortamın havası boşaltılır. $15 \mathrm{ml}$ TFE çözgeni ilave edildikten sonra vanalar kapatilır ve ekstraksiyon kabı ayrılarak $2 \mathrm{dk}$ vortekslenir. Ekstraksiyon kabı içerisindeki TFE ve toluen bir behere akıtılır. Beher içerisindeki TFE çözgeni buharlaşarak kalan toluen vial içerisine alınır ve 3 Dedektörlü GC (HP 6890 GC, 
G.T. Bakırcı vd. / Yaş Üzümde Pestisit Kalıntılarının GC [Çoklu-Dedektörlere( $\mu$-ECD, MSD, Dual-FPD) sahip gaz kromatografisi] ile Çoklu Kalıntı Tayini için Analiz Yönteminin Geliştirilmesi

$\mu$-ECD, Dual FPD, 5975 MSD) cihazina verilir.

Geri kazanım çalışmalarında temiz olduğu bilinen örneklere aktif maddelerin Türk Gıda Kodeksi'nde yer alan maksimum kalıntı limitleri göz önünde bulundurularak farklı 3 konsantrasyonda standart ekleme yapılmıştır. Çalışılan tüm pestisitlerin MRL değerlerini kapsayacak şekilde 3 Dedektörlü GC (HP 6890 GC, $\mu$-ECD, Dual FPD, 5975 MSD) cihazı için 10 100 - $500 \mathrm{ng} / \mathrm{ml}$ seviyelerinde standart ekleme işlemi yapılmıştır. $10 \mathrm{~g}$ tartılan örnek içerisine standart karışımı ilave edilerek vortexde $2 \mathrm{dk}$ karıştırılıp homojen bir şekilde dağılması sağlanmış ve pestisitlerin örnek matriksine tamamen geçişini sağlamak amacı ile 5 dakika bekletildikten sonra ekstraksiyon işlemine geçilmiştir. Her bir seviye için 5 tekrarlı çalışma gerçekleştirilmiş olup sonuçların istatistiksel analizi Microsoft Excel ile yapılmıştır.

Geliştirilen metodun geçerliliğinin sağlanması amacı ile laboratuar-içi validasyon yapılmış ve performans karekteristikleri çalışılmıştır. Doğrusallık, gözlenebilme sinırı (LOD), tayin sınırı (LOQ), doğruluk ve kesinlik ile standart ekleme (fortifikasyon) yapılan örneklerden geri kazanım değerleri belirlenmiştir.

\section{Bulgular}

$\mathrm{Bu}$ çalışmada, ülkemizde yaş üzümde pestisit kalıntılarının tayini için hızlı, ucuz, kolay, güvenli, etkili, kesin sonuç veren ekstraksiyon ve çoklu kalıntı analiz yöntemi geliştirilmiştir. Öncelikle pestisit saf standartları toluende çözülerek 3 Dedektörlü GC (HP 6890 GC, $\mu$-ECD, Dual FPD, 5975 MSD) cihazına verilmiş ve analiz edilecek etkili maddelerin alıkonma zamanları tespit edilerek 5 farklı standart karışımı oluşturulmuştur.
Türk Gıda Kodeksi ve Avrupa Birliği regülasyonları dikkate alınarak denetim ve izleme programlarında izlenmesi gerekli ve ülkemizdeki ihracat ürünlerinde kontrol edilen aktif maddeler ile yasaklı aktif maddeler hedef alınarak izomerleri ile birlikte toplam 61 etkili madde için çalışmalar yapılmıştır.

\subsection{Geliştirilen Metodun Geçerli} Kılınması (validasyonu)

Geliştirilen metodun geçerliliğinin sağlanması amacı ile laboratuar-içi validasyon yapılmış olup performans karekteristikleri çalıșılmıștır.

Gözlenebilme Sınırı (LOD) ve Tayin Sinırı (LOQ)

Validasyonda her bir etkili madde için gözlenebilme sınırı (LOD) ve tayin sınırı (LOQ) değerleri hesaplanarak, yasal mevzuatta belirtilen MRL değerleri ile uyumluluğu kontrol edilmiştir. LOQ değerlerinin tespiti için 3 dedektörlü GC cihazı için $10 \mathrm{ng} / \mathrm{ml}$ seviyesinde 10 tekrarlı çalışmalar gerçekleştirilmiştir. SANTE/11813/2017 [17] dokümanına göre çalışmalar sonucunda metot kapsamındaki tüm bileşikler için, tekrarlanabilirlik RSDr $\leq \% 20$ olmak üzere, kabul edilebilir geri kazanımlar \%70-120 aralığında bulunmuş olup tüm aktif maddeler için LOQ değerlerinin MRL değerleri altında olduğu tespit edilmiştir.

Doğrusallık (Lineerlik), lineer aralık, kalibrasyon eğrisi ve korelasyon katsayısı $\left(R^{2}\right)$

Lineer aralık çalıșılan konsantarasyon aralığını ifade etmektedir. Bu çalışmada 3 Dedektörlü GC (HP 6890 GC, $\mu$-ECD, Dual FPD, 5975 MSD) cihazı için 100$5000 \mathrm{ng} / \mathrm{ml}$ arasinda 7 farklı konsantrasyonda matriks etkili (matrix matched) kalibrasyon grafikleri oluşturulmuştur. Oluşturulan kalibrasyon grafiklerinin korelasyon katsayıları 0, 99 değerinden büyüktür. Ancak çoklu kalıntı analiz metotlarında 
G.T. Bakırcı vd. / Yaş Üzümde Pestisit Kalıntılarının GC [Çoklu-Dedektörlere( $\mu$-ECD, MSD, Dual-FPD) sahip gaz kromatografisi] ile Çoklu Kalıntı Tayini için Analiz Yönteminin Geliştirilmesi

bazı durumlarda sapmalar belirlemiştir. ABD, Kanada, Almanya ve görülmektedir. Bu durum etkili bazı AB ülkeleri ve bölgesel uluslar arası maddelerin kimyasal yapılarına bağlı örgütler, çeşitli tarım ve gıda olarak çabuk bozulması sonucu pestisitin kararlılığı ve stabilitesinin zarar görmesi ve sonuçlar arasında farklılık oluşmasına sebep olmaktadır.

Doğruluk, ekstraksiyon verimi, \% geri kazanım (recovery);

Doğruluk, bir ölçüm cihazının veya metodun ölçüm sonucunun gerçek değere ve birbirlerine yakınlığını ifade etmek için kullanılır. Gerçek değerden, bulunan değerin çıkarılması ile elde edilen değerin gerçek değere oranının 100 ile çarpımı, \% doğruluk değerini vermektedir.

Doğruluk için 3 farklı konsantrasyonda, 3 Dedektörlü GC (HP 6890 GC, $\mu$-ECD, Dual FPD, 5975 MSD) cihazı için 10 100 - $500 \mathrm{ng} / \mathrm{ml}$ seviyesinde standart ekleme işlemi yapılmıştır.

Tekrarlanabilirlik standart sapma ve \%RSD değerlerinin hesaplanabilmesi amacı ile yaş üzüm matriksi için 10-50$100 \mathrm{ng} / \mathrm{ml}$ seviyelerinde standart ekleme işlemi ile n:5 li olacak şekilde gerçekleștirilmiş olup sonuçlar Ek A da verilmiştir.

\section{Tartışma ve Sonuç}

İnsan sağlığı ve gelişimi için büyük önem taşıyan gıda güvenliği ve hijyen, farklı ülkeler ve ilgili uluslar arası kurumlar için de endişe sebebi olan büyük bir sorundur. Dünya Sağlı Örgütü (WHO), uluslararası halk sağlığı planlarının ilk siralarında gida güvenliğine yer vermiștir. Bu kapsamda, gıda ürünlerinde bulunan pestisit ve hayvansal ilaçlar, gıda güvenliğinde risk oluşturmaktadır. Gıda güvenliğini sağlamak amacıyla, Gıda ve Tarım Örgütü (FAO)/WHO/Codex Alimentarius Commission (CAC), yaklaşık 300 çeşit tarım ürünü ve gıda ürününde, 170'i aşkın pestisit ve hayvansal ilaç için maksimum kalıntı ürünlerinde, ülkelere veya yerel koşullara göre, pestisit ve hayvansal ilaçlar için kendi MRL değerlerini belirtmişlerdir. Farklı ülkelerden araştırmacılar, birkaç pestisitin kalıntılarını tespit etmek için yöntem geliştirmişlerdir. Özellikle son 20 yılda, çoklu kalıntı analitik yöntemleri yoğun bir şekilde araştırılmıştır. Meyve ve sebze gibi tarım ürünlerinde, 20 farklı çoklu kalıntı yöntemini karşılaştırmak amacı ile bir çalışma gerçekleştirilmiştir. Mevcut çoklu kalıntı yöntemleri, ekstraksiyon aşamasında kullanılan çözücülere göre (aseton, etil asetat, asetonitril) sinıflandırılmıştır.

En yaygin aseton ekstraksiyon yöntemlerinden biri, Luke ve ark. [18] tarafından sunulmuştur. $\mathrm{Bu}$ yöntemde, ekstraksiyon için aseton, sıvı-sıvı partisyon diklorometan-petroleteri kullanılarak gerçekleştirilmiş ve temizleme aşaması florisil ile yapılmıştır. GC-ECD ile organik klorlu, nitrojenli, kükürtlü pestisitler tespit edilirken, organik fosforlu pestisitlerin tespiti için GC-FPD cihazı kullanılmıştır. Luke ve ark.'larının yöntemiyle, 79 pestisit kalıntısı analiz edilmiştir. Stan ve Linkerhagner [19] tarafından aseton ile ekstraksiyon sonrası, diklorometan ile sıvı-sıvı partisyon aşaması ve GPC yöntemi ile temizleme aşamasını gerçekleştirdikten sonra, GC-AED (Atomic Emission Detector) kullanarak 385 pestisitin sonucu verilebilmektedir. Aseton ile ekstraksiyonun ardından, etil-asetat-cyclohexane ile sıvı-sıvı partisyon aşaması yapılmıș, GPC yöntemi ile temizleme aşaması gerçekleştirilmiştir. 3 farklı GC dedektörü (ECD, NPD ve MSD) kullanılması sonucunda 400 pestisit analiz edilmiștir. 
G.T. Bakırcı vd. / Yaş Üzümde Pestisit Kalıntılarının GC [Çoklu-Dedektörlere( $\mu$-ECD, MSD, Dual-FPD) sahip gaz kromatografisi] ile Çoklu Kalıntı Tayini için Analiz Yönteminin Geliştirilmesi

Gamon ve ark. [20] aseton ile petisit tespit etmiştir. Machodo ve ark. ekstraksiyon sonrası, diklorometanpetrol eteri ile sıvı-sıvı partisyon aşaması ve GC/MS/MS elektron impact (EI) veya kimyasal iyonizasyon (CI) yöntemi ile 80 adet organik fosforlu, organik klorlu, nitrojenli ve pyretroidli pestisitleri analiz etmiştir. Gelsomino ve ark. [21] aseton ile ekstraksiyon sonrası, diklorometan ile sıvi-sıvı partisyon aşaması ve GPC yöntemi ile temizleme aşaması gerçekleştirilmiştir. GC-ECD ile 77 adet pestisit analiz edilmiş ve GC/MS ile konfirme edilmiştir.

Etil asetat da çok yaygın bir çoklu kalıntı ekstraksiyon çözücüsüdür. Krijgsmann ve ark. [22] etil asetat ile ekstraksiyon sonrası GC kolon kullanarak separasyon gerçekleştirdikten sonra, FPD yöntemi ile 59 adet organik fosforlu pestisiti analiz etmiştir. Son olarak, Stan ve Goebel [23] bu yöntemleri ve ardından NPD ve ECD kullanarak 83 adet organik fosforlu ve organik klorlu pestisit analiz etmiştir. Holstege ve ark. [24] etil asetat ile ekstraksiyon sonrası, GPC veya SPE temizleme aşaması sonrası, GC ve LC yöntemleriyle 43 adet organik fosforlu, 17 adet organik klorlu, ve 11 adet $\mathrm{N}$ metil- karbamat pestisit analiz edilmiștir. $\mathrm{Bu}$ yöntem, meyve, sebze ve hayvan dokularına uygulanabilmektedir. Obana ve ark. [25,26] aktif karbonlu kartuş ile GPC temizleme aşaması sonrası, GC-MSD ve GC-FPD yöntemleri ve floresans detektörlü LC yöntemiyle meyve ve sebzelerde 110 pestisit kalıntısı analiz etmiştir. Aguera ve ark. [27] aynı yöntemi, temizleme aşaması olmaksızın gerçekleştirmiş, GC/MS/MS yöntemiyle, sebze ve meyvelerde 55 adet organik fosforlu, organik klorlu ve piretroid pestisit kalıntısı analiz etmiştir. Guedes ve ark [3] QuEChERS pestisit ekstraksiyon yöntemi ile çalışmış olup tropik guava meyvesinde 0,1 ile 0,5 $\mathrm{mg} / \mathrm{kg}$ arasındaki seviyelerde 5 farklı [28] Enginar numunelerinde 3 farklı metot kıyaslaması yapmış ve modifiye QuEChERS metodunun en iyi performans gösterdiği tespit edilmiştir. Son zamanlarda, pestisit kalıntı ekstraksiyonu için asetonitril kullanımına ağırlık verilmiştir. Liao ve ark. [29] asetonitril ile pestisit kalıntı ekstraksiyonu sonrası, sodyum klorür ile temizleme gerçekleştirilmiș, GC/MS yöntemiyle 143 adet pestisit analiz edilmiştir. Anastassiades ve ark. [30] QuEChERS yöntemini geliştirmek için sistematik bir çalışma gerçekleştirmiş olup pestisit kalıntı analizleri için asetonitril kullanmıştır. Sonraki aşamada $\mathrm{MgSO} 4$ ve $\mathrm{NaCl}$ ile su uzaklaştırılmış, temizleme aşaması PSA sorbent kullanarak SPE kartuşu ile yapılmış ve gıdalarda GC/MS ve LC/MS/MS yöntemleriyle 229 adet pestisit analiz edilmiştir. Fillion ve ark. [31,32] SPE kartuşu ile temizleme aşaması sonrası, LC ile 251 adet pestisit kalıntısının analizini gerçekleştirmiştir. Geçmişte, Pang ve ark. [33,34,35] piretroidli pestisitlerin analizi için, 5 farklı çoklu kalıntı yöntemi geliştirmiştir. Bu yöntemlerde, ayrı ayrı ekstraksiyon çözücüsü olarak asetonpetrol eteri, metanol, aseton, asetonitril; Florisil kolonu ile temizleme kullanılmıștır. GC-ECD, GC-MSD ve LCUV yöntemleriyle, tarım ürünlerinde 811 adet piretroid pestisit kalıntıları analiz edilmiştir. Analiz metodu laboratuar arası kollaboratif bir çalışma ile geliştirilmiştir. 6 ülkeden 14 laboratuar katılmış ve AOAC Resmi Yöntemi oluşturulmuştur.

Günümüzde analizlerde kullanılan pek çok metodun uzun zaman alması, pahalılığı, nicel tayinin zorluğu, tekrarlanabilirliğinin düşük olması, etkinliğinin az ve atığının fazla olması gibi bir çok olumsuz yönleri vardır. $\mathrm{Bu}$ sebeplerden dolayı doğruluk, 
G.T. Bakırcı vd. / Yaş Üzümde Pestisit Kalıntılarının GC [Çoklu-Dedektörlere( $\mu$-ECD, MSD, Dual-FPD) sahip gaz kromatografisi] ile Çoklu Kalıntı Tayini için Analiz Yönteminin Geliştirilmesi

hassasiyet, geniş kullanılabilirlik, Dual FPD, 5975 MSD) cihazı için 100ucuzluk, kesinlik, hızlı ve kolay $5000 \mathrm{ng} / \mathrm{ml}$ arasında 7 farklı uygulanabilir olma gibi yeni konsantrasyonda matriks etkili (matrix yaklaşımlara gereksinim duyulmuştur. $\mathrm{Bu}$ çalışmada, yaş üzümdeki pestisit kalıntılarının Çoklu-Dedektörlere (uECD, MSD, dual-FPD) sahip gaz kromatografisiyle eş-zamanlı tayini için hızlı, ucuz, kolay, güvenli, etkili, kesin sonuç veren ekstraksiyon ve analiz yönteminin geliştirilmesine çalışılmış, yapılan validasyon çalışmaları neticesinde metodun geçerli kılınması sağlanmiștır.

Geliştirilen çoklu kalıntı analiz metodunda $10 \mathrm{~g}$ örnek ile basınç altında sıvı 1,1,1,2-Tetrafluoroethane (TFE) çözgeni kullanılarak ekstraksiyon yapılmaktadır. Eş zamanlı tayine olanak veren metodun diğer çoklu kalıntı analiz metotlarına göre pek çok avantajı bulunmaktadır. Analiz metodunun maliyetinin çok düşük olması ve yüksek geri kazanıma sahip olması en önemli avantajı olup diğer analiz metodlarına göre analiz süresi oldukça kısadır. Ekstraksiyon için $15 \mathrm{ml}$ TFE çözgeni ve $1 \mathrm{ml}$ toluen yeterlidir ve numune başına kimyasal gideri çok düşüktür. Metodun diğer önemli avantajı ise $10 \mathrm{~g}$ örnekteki kalıntının $1 \mathrm{ml}$ toluen içerisinde tutulması olup, miktarın 10 kat deriştirilmesidir. Bunun sonucunda çok düşük tespit limitlerine inebilen cihazlara gerek kalmamaktadır.

Aktif maddelerin Çoklu-Dedektörlere (u-ECD, MSD, dual-FPD) sahip gaz kromatografisiyle eş-zamanlı tayini için cihaz parametreleri ve koşulları ayarlandıktan sonra metodun geçerli kılınma (validasyon) çalışmaları yapılmıştır. Laboratuvar içi metot geçerli kılma parametreleri gözlenebilme sınırı (LOD), tayin sınırı (LOQ), doğruluk ve kesinlik üzerinde çalışılmış, hesaplamalar gerçekleştirilmiştir. Pestisitlerin 3 Dedektörlü GC (HP 6890 GC, $\mu$-ECD, matched) kalibrasyon grafikleri oluşturulmuştur. Çizdirilen kalibrasyon grafiklerinin korelasyon katsayıları (R2) 0.99 un üzerindedir. Çoklu kalıntı analiz çalışmalarında 0.98'in üzerinde olması şartı bulunmaktadır [36,37,38].

Doğruluk parametresine yönelik olarak 10-100-500 ng/ml seviyelerinde standart ekleme işlemi yapılarak geri kazanım, standart sapma ve relatif standart sapma (RSD) değerleri hesaplanmıştır. Pestisit analizlerinde geri kazanım değerlerinin \%70-120 arasında relatif standart sapma değerinin ise $\% 20$ altında olması önerilmektedir. Bununla birlikte, \%60140 genelleștirilmiş aralığı rutin çoklu kalıntı analizi için kullanılabilmektedir. Eğer aktif madde miktarı 0,01 ppm den az ise tekrarlanabilirlikte relatif standart sapma (RSD) \%30 a kadar kabul edilmektedir [36]. Çalışmada bu değerler göz önüne alınarak değerlendirme yapılmıştır.

$\mathrm{Bu}$ çalışmada geliştirilen ekstraksiyon ve çoklu kalıntı analiz metodu ile pestisitleri eş zamanlı tayininin yapılabilmesi gerçekleştirilmiş ve isomerleri ile birlikte toplam 61 etkili maddenin 3 Dedektörlü GC (HP 6890 GC, $\mu$-ECD, Dual FPD, 5975 MSD) cihazı ile doğrulama ve kantitasyonu sağlanmıştır.

Geliştirilen çoklu kalıntı analiz metodunun devaminda toluende çözülebilen diğer aktif maddelerin verifikasyon çalışmaları gerçekleştirilerek sayının arttırılabileceği, meyve ve sebze matriksleri dışında diğer tarımsal ürünlerde de metodun uygulanabilirliğinin araştırılması, elde edilen veriler ışığında değerlendirmelerin yapılarak geniş kapsamlı bir çoklu kalıntı analiz 
G.T. Bakırcı vd. / Yaş Üzümde Pestisit Kalıntılarının GC [Çoklu-Dedektörlere( $\mu$-ECD, MSD, Dual-FPD) sahip gaz kromatografisi] ile Çoklu Kalıntı Tayini için Analiz Yönteminin Geliştirilmesi

metodunun oluşturulması ve uluslar arası çapta tanıtılarak uygulamaya geçirilmesi düşünülmektedir.

\section{Kaynakça}

[1] Yücel, Ü., 2007. Pestisitlerin İnsan ve Çevre Üzerine Etkileri. Nükleer Araştırma ve Eğitim Merkezi, Nükleer Kimya Bölümü. Ankara. (Online)

http://www.dogainsanisbirligider negi.org.tr/makaleler/pestisi tler.doc (17 Ekim 2009).

[2] Fosu P.O., Donkor A., Ziwu C., Dubey B, Adaboh R.K., Asante I., Nyarko S., Tawiah R., Nazzah N., 2017, Surveillance of pesticide residues in fruits and vegetable from Accra Metropolis markets, Ghana, 2010-2012: a case study in Sub-Saharan Africa

[3] Guedes J.A.C, Silva R.O., Lima C.G., Milhome M.A.L, Nascimento R.F., 2016, Matrix effect in guava multiresidue analysis by QuEChERS method and gas chromatography coupled to quadrupole mass spectrometry, Food Chemistry 199, 380-386.

[4] Anonymous, 1991, European Commission, Council Directive of 15 July 1991 (91/414/EEC) concerning the placing of plant protection

[5] 1253-1259 available from: ISI:000222925400025

[6] Dejonckheere, W., Steurbaut, W., Drieghe, S., Verstraeten, R., Braeckman, H., 1996, Pesticide residue concentrations in the Belgian total diet, 1991-1993. Journal of AOAC International, 79, (2) 520-528 available from: ISI:A1996UD26800026

[7] Elkins, E., R.,1989. Effect of Commercial Processing on
Pesticide-Residues in Selected Fruits and Vegetables. Journal of the Association of Official Analytical Chemists, 72, (3) 533535 available from: ISI:A1989U556600036

[8] Krol, W., J., Arsenault, T., L., Pylypiw, H., M., Mattina, M., J., I., 2000. Reduction of pesticide residues on produce by rinsing. Journal of Agricultural and Food Chemistry, 48, (10) 4666-4670 available from: ISI:000089957200034

[9] Schattenberg, H., J., Geno, P., W., Hsu, J., P., Fry, W., G., Parker, R., P. 1996. Effect of household preparation on levels of pesticide residues in produce. Journal of AOAC International, 79, (6) 1447 1453 available from: ISI:A1996VU05000028.

[10] Golge 0, Kabak B., 2018, Pesticide Residues in Table Grapes and Exposure Assessment, J. Agric. Food Chem. 66, 1701-1713.

[11] Anonymous, 2007, Tarım İlaçları Kongre ve Sergisi Bildiriler Kitabı, p. 60

[12] Demircan, V., ve Yllmaz, H., 2005 Isparta ili elma üretiminde tarımsal ilaç kullanımının çevresel duyarlılık ve ekonomik açıdan analizi, Ekoloji, 14, 57, 15-25

[13] Çiçek, A. ve Erkan, O., 1996, Tarım ekonomisinde araştırma ve örnekleme yöntemleri, Gaziosmanpaşa Üniversitesi, Ziraat Fakültesi Yayınları, No:12, Tokat

[14] Ferna'ndez-Alba, A., R., 2004, Chromatographic-Mass Spectrometric Food Analysis for Trace Determination of Pesticide Residues, Comprehensive Analytical Chemistry, Vol. XLIII, 
G.T. Bakırcı vd. / Yaş Üzümde Pestisit Kalıntılarının GC [Çoklu-Dedektörlere( $\mu$-ECD, MSD, Dual-FPD) sahip gaz kromatografisi] ile Çoklu Kalıntı Tayini için Analiz Yönteminin Geliştirilmesi

Elsevier, Amsterdam, The by gel permeation chromatography Netherlands followed by gas chromatography

[15] Anonymous, 2006, www.agilent.com/chem Identification Pesticides with Full Scan, SIM, $\mu$-ECD, and FPD From a Single Injection. Agilent Technologies, Application, Food Safety, Environmental. 2850 Centerville Road, Wilmington, DE 19808-1610, USA

[16] European Commission SANTE, 2017. Guidance document on analytical quality control and method validation procedures for pesticide residues and analysis in food and feed. Document SANTE/11813/2017, Supersedes SANTE/11945/2015. 1 January 2018.

[17] Luke, M., Froberg, J. A., And Masumoto,H., T, 1975, J. Assoc. Off. Anal. Chem., 58; 1020-1026

[18] Stan, H., J., Linkerhägner,M., 1996, Pesticide residue analysis in foodstuffs applying capillary gas chromatography with atomic emission detection State-of-the-art use of modified multimethod S19 of the Deutsche Forschungsgemeinschaft and automated large-volume injection with programmed-temperature vaporization and solvent venting, Journal of Chromatography A, Vol.750, p. 369-390

[19] Gamon, M., Lleo, C., 2001, Multiresidue Determination of Pesticides in Fruit and Vegetables by Gas Chromatography/Tandem Mass Spectrometry, J. AOAC Int., Vol. 84, No: 4, p. 1209-1216

[20] Gelsomino, A., Petrovicová, B., Tiburtini, S., Magnani, E., Felici, M., 1997, Multiresidue analysis of pesticides in fruits and vegetables with electron-capture and mass spectrometric detection, Journal of Chromatography A, Vol.782, p. 105-122

[21] Krijgsman, W., Van De Kamp, C., G., 1976, Analysis of organophosphorus pesticides by capillary gas chromatography with flame photometric detection, Journal of Chromatography A, Vol.117, p. 201-205

[22] Stan, H., J., Goebel, H., 1983, Automated capillary gas chromatographic analysis of pesticide residues in food, Journal of Chromatography A, Vol.268, p. 55-69

[23] Holstege, D., Scharberg, D., L., Tor, E., R., 1994, A rapid multiresidue screen for organophosphorus, organochlorine and $\mathrm{N}$-methylcarbamates in plant and animal tissues, J. AOAC Int, Vol. 77, p.12631274

[24] Obana, H., Akutsu, K., Okihashi, M., Kakimoto, S., Hori, S., 1999, Multiresidue analysis of pesticides in vegetables and fruits using a high capacity absorbent polymer for water, Analyst, 124, p. 11591165

[25] Obana, H., Akutsu, K., Okihashi, M., Kakimoto, S., Hori, S., 2001, Multiresidue analysis of pesticides in vegetables and fruits using twolayered column with graphitized carbon and water absorbent polymer, Analyst, 126, p. 15291534

[26] Aguera, A., Contreras, M., Crespo, J., Fernández-Alba, A., R., 2002, Multiresidue method for the analysis of multiclass pesticides in agricultural products by gas 
G.T. Bakırcı vd. / Yaş Üzümde Pestisit Kalıntılarının GC [Çoklu-Dedektörlere( $\mu$-ECD, MSD, Dual-FPD) sahip gaz kromatografisi] ile Çoklu Kalıntı Tayini için Analiz Yönteminin Geliştirilmesi

chromatography-tandem mass spectrometry, Analyst, 127 , p. 347354

[27] Machado I, Gérez N., Pistón M., Heinzen H., Cesio M.V., 2017, Determination of pesticide residues in globe artichoke leaves and fruits by GCMS and LC-MS/MS using the same QuEChERS procedure, Food Chemistry, PII: S0308-8146(17)30025-0

[28] Liao W, Joe T, Cusick WG. 1991. Multiresidue screening method for fresh fruits and vegetables with gas chromatographic/mass spectrometric detection. J Assoc Off Anal Chem, 74, p. 554-565.

[29] Anastassiades, M., Lehotay, S.J., Štajnbaher, D. and Schenck, F.J., 2002, Quick, Easy, Cheap, Effective, Rugged and Safe (QuEChERS) Approach for the Determination of Pesticide Residues. Florida Pesticide Residue Workshop.

[30] Fillion, J., Hindle, R., Lacroix, M. and Selwyn, J., 1995, Multiresidue determination of pesticides in fruit and vegetables by gas chromatpgraphy - mass selective detection and liquid chromatography with fluorescence detection, Journal of AOAC International, Vol. 78, No. 5, 1252 1266.

[31] Fillion, J., Saure, F. and Selwyn, J., 2000, Multiresidue methods for the determination of residues of 251 pesticides in fruits and vegetables by gas chromatography with florescence detection. J. AOAC Int., Vol. 83: 698-713

[32] Pang, G.F., T.S. Zhao, Y.Z. Chao And C.L. Fan. 1994. Cleanup with two florisil columns for gas chromatographic determination of multiple pyrethroid insecticides in products of animal origin, J. of AOAC Intemational, Vol. 77, p. 1634 - 1638.

[33] Pang, G., F., Chao,Y., Z., Liv, X., S., Fan, C., 1995, Multiresidue liquid chromatographic method for simultaneous determination of pyrethroid insecticides in fruits and vegetables.J. of AOAC International, Vol. 78, p. 1474 1480.

[34] Pang, G.F., Chao, Y.Z., Fan, C., L.., Zhang, J.J., Li, X., M., 1999, Multiresidue Gas Chromatographic Method for Determining Synthetic Pyrethroid Pesticides in Agricultural Products: Collaborative Study, Journal of AOAC International, Vol. 82, pags. 186-212

[35] Anonymous, 2000, European Commission Working Document on"Residues: Guidance for generating and reporting methods of analysis in support of preregistration data requirements for Annex II (part A, Section 4) and Annex III (part A, Section 5) of Directive 91/414", EC SANCO/3029/99, 11/07/2000, 26 pages

[36] AOAC, 2002, AOAC International Methods Committee Guidelines for validation of Qualitative and Quantitative Food Official Methods of Analysis, Journal of AOAC International, 85 (5): 1187 - 1200.

[37] IUPAC, 2002, Harmonized guidelines for single-laboratory validation of methods of analysis. International Union of Pure and Applied Chemistry (Pure Appl. Chem.), Vol. 74, No. 5, 835-855.

[38] Anonymous, 2000, European Commission Working Document on"Residues: Guidance for 
G.T. Bakırcı vd. / Yaş Üzümde Pestisit Kalıntılarının GC [Çoklu-Dedektörlere( $\mu$-ECD, MSD, Dual-FPD) sahip gaz kromatografisi] ile Çoklu Kalıntı Tayini için Analiz Yönteminin Geliştirilmesi

generating and reporting methods

of analysis in support of preregistration data requirements for Annex II (part A, Section 4) and Annex III (part A, Section 5) of Directive 91/414", EC SANCO/3029/99, 11/07/2000, 26 pages

\section{Ekler}

Ek A. Yaş Uzum matriksinde 3 Dedektörlü GC (HP 6890 GC, $\mu$-ECD, Dual FPD, 5975 MSD) de analiz edilen aktif maddelerin standart ekleme seviyeleri ve geri kazanım ile relatif standart sapma yüzdeleri $(n=5)$

Ek A. Yaş üzüm matriksinde 3 Dedektörlü GC (HP 6890 GC, $\mu$-ECD, Dual FPD, 5975 MSD) de analiz edilen aktif maddelerin standart ekleme seviyeleri ve geri kazanım ile relatif standart sapma yüzdeleri $(\mathrm{n}=5)$

\begin{tabular}{|c|c|c|c|c|c|c|c|c|c|}
\hline \multirow{2}{*}{$\begin{array}{c}\text { Aktif Madde } \\
\text { (GC/ } \mu \text {-ECD, MSD, } \\
\text { dual-FPD) }\end{array}$} & \multicolumn{3}{|c|}{$\begin{array}{l}\text { 1.standart ekleme seviyesi } \\
(0,01 \mathrm{mg} / \mathrm{kg})\end{array}$} & \multicolumn{3}{|c|}{$\begin{array}{l}\text { 2.standart ekleme seviyesi } \\
(0,10 \mathrm{mg} / \mathrm{kg})\end{array}$} & \multicolumn{3}{|c|}{$\begin{array}{l}\text { 3.standart ekleme seviyesi } \\
(0,50 \mathrm{mg} / \mathrm{kg})\end{array}$} \\
\hline & ort.rec. (\%) & std.sapma & $\%$ RSD & ort.rec. (\%) & $\begin{array}{l}\text { std.sa } \\
\text { pma }\end{array}$ & $\%$ RSD & $\begin{array}{l}\text { ort.rec. } \\
(\%)\end{array}$ & std.sapma & $\%$ RSD \\
\hline pentachlorobenzene & 95,8 & 0,0003 & 2,99 & 99,48 & 0,002 & 1,93 & 99,11 & 0,008 & 1,65 \\
\hline tecnazene & 129,4 & 0,0006 & 4,9 & 95,54 & 0,005 & 4,83 & 98,73 & 0,01 & 2,04 \\
\hline alpha $\mathrm{HCH}$ & 139,4 & 0,0005 & 3,6 & 89,94 & 0,01 & 11,45 & 101,89 & 0,01 & 1,92 \\
\hline gamma $\mathrm{HCH}$ & 142 & 0,0004 & 2,86 & 93,98 & 0,002 & 2,2 & 101,76 & 0,011 & 2,25 \\
\hline chlorothalonil & 76 & 0,0004 & 4,88 & 100,14 & 0,002 & 2,45 & 104,09 & 0,014 & 2,75 \\
\hline dichlofenthion & 108,8 & 0,0013 & 11,94 & 122,24 & 0,002 & 1,79 & 108,91 & 0,009 & 1,64 \\
\hline fenchlorphos & 125,8 & 0,0005 & 4,01 & 102,24 & 0,002 & 2,18 & 103,41 & 0,014 & 2,72 \\
\hline aldrin & 131,6 & 0,0001 & 0,82 & 97 & 0,001 & 1,26 & 101,18 & 0,007 & 1,33 \\
\hline parathion ethyl & 94,2 & 0,0013 & 13,77 & 133,98 & 0,004 & 3,03 & 109,6 & 0,009 & 1,66 \\
\hline chlozolinate & 136,4 & 0,0003 & 2,42 & 98,64 & 0,002 & 1,87 & 103,8 & 0,008 & 1,56 \\
\hline alpha endosulfane & 121,8 & 0,0002 & 1,59 & 105,34 & 0,006 & 5,74 & 103,2 & 0,017 & 3,35 \\
\hline dieldrin & 133,4 & 0,0002 & 1,18 & 99,12 & 0,001 & 1,42 & 102,84 & 0,007 & 1,33 \\
\hline beta endasulfane & 115,4 & 0,0002 & 2,13 & 100,02 & 0,002 & 1,65 & 102,82 & 0,007 & 1,36 \\
\hline endosulfan sulfate & 124 & 0,0003 & 2,34 & 98,16 & 0,002 & 1,87 & 101,72 & 0,008 & 1,51 \\
\hline bromopropylate & 101,6 & 0,0002 & 2,42 & 101,9 & 0,002 & 1,79 & 102,06 & 0,006 & 1,2 \\
\hline lambda cyhalothrin & 132 & 0,0006 & 4,82 & 97,44 & 0,002 & 1,58 & 108,84 & 0,007 & 1,32 \\
\hline permethrin isomer1 & 112 & 0,0007 & 6,1 & 124,88 & 0,016 & 12,55 & 112,21 & 0,037 & 6,68 \\
\hline permethrin isomer2 & 64,8 & 0,0008 & 11,88 & 120,14 & 0,003 & 2,9 & 113,62 & 0,039 & 6,9 \\
\hline permethrin toplam & 88,4 & 0,0006 & 6,55 & 122,51 & 0,007 & 6,01 & 112,92 & 0,038 & 6,79 \\
\hline fenvalerate isomer 1 & 124,6 & 0,0008 & 6,7 & 100,02 & 0,001 & 1,45 & 108,25 & 0,005 & 0,91 \\
\hline fenvalerate isomer2 & 86,4 & 0,001 & 11,3 & 109,92 & 0,002 & 1,66 & 107,74 & 0,02 & 3,7 \\
\hline fenvalerate toplam & 105,5 & 0,0007 & 6,4 & 104,97 & 0,001 & 1,43 & 108 & 0,012 & 2,21 \\
\hline
\end{tabular}


G.T. Bakırcı vd. / Yaş Üzümde Pestisit Kalıntılarının GC [Çoklu-Dedektörlere( $\mu$-ECD, MSD, Dual-FPD) sahip gaz kromatografisi] ile Çoklu Kalıntı Tayini için Analiz Yönteminin Geliştirilmesi

\begin{tabular}{|c|c|c|c|c|c|c|c|c|c|}
\hline trifluralin & 60,92 & 0,0005 & 8,18 & 96,28 & 0,002 & 2,34 & 100,46 & 0,012 & 2,45 \\
\hline pentachloroanisole & 71,8 & 0,0002 & 3,4 & 94,68 & 0,002 & 2,38 & 101,35 & 0,015 & 2,87 \\
\hline pentachloroaniline & 76,2 & 0,0002 & 3,2 & 90,86 & 0,003 & 2,85 & 101,91 & 0,019 & 3,72 \\
\hline vinclozolin & 72 & 0,0009 & 12,11 & 103,18 & 0,006 & 5,97 & 100,57 & 0,012 & 2,31 \\
\hline fenithrothion & 68,4 & 0,0004 & 5,21 & 88,04 & 0,005 & 5,66 & 109,69 & 0,021 & 3,74 \\
\hline bromophos methyl & 84,6 & 0,0011 & 13,15 & 85,68 & 0,003 & 3,57 & 101,89 & 0,022 & 4,22 \\
\hline procymidone & 74,2 & 0,0004 & 5,92 & 92,18 & 0,005 & 5,31 & 98,29 & 0,031 & 6,29 \\
\hline prothiophos & 101 & 0,0003 & 2,56 & 88,78 & 0,002 & 2,35 & 99,42 & 0,014 & 2,73 \\
\hline oxyfluorfen & 87,2 & 0,0003 & 3,38 & 102,4 & 0,002 & 2,25 & 100,18 & 0,014 & 2,88 \\
\hline op DDT & 100 & 0,0004 & 3,53 & 93,84 & 0,002 & 2,56 & 103,19 & 0,017 & 3,25 \\
\hline pp DDT & 95,8 & 0,0012 & 12,22 & 82,84 & 0,004 & 5 & 115,14 & 0,049 & 8,48 \\
\hline iprodione & 52,8 & 0,001 & 18,01 & 74,78 & 0,009 & 12,68 & 104,63 & 0,035 & 6,7 \\
\hline beta cyfluthrin & 119,4 & 0,0003 & 2,27 & 85,98 & 0,003 & 3,11 & 101,1 & 0,019 & 3,74 \\
\hline tau fluvalinate isomer1 & 84,8 & 0,0003 & 3,37 & 69,26 & 0,009 & 12,76 & 101,19 & 0,041 & 8,15 \\
\hline tau fluvalinate isomer2 & 85,6 & 0,0003 & 3,27 & 76,92 & 0,004 & 4,92 & 102,44 & 0,022 & 4,32 \\
\hline tau fluvalinate toplam & 85,2 & 0,0002 & 2,67 & 73,09 & 0,004 & 5,92 & 101,81 & 0,031 & 6,08 \\
\hline hexachlorobenzene & 73,6 & 0,0004 & 5,63 & 82,55 & 0,002 & 1,98 & 84,52 & 0,009 & 2,23 \\
\hline beta $\mathrm{HCH}$ & 99,8 & 0,0004 & 3,92 & 81,36 & 0,003 & 3,08 & 84,64 & 0,011 & 2,57 \\
\hline heptachlor & 114,4 & 0,0004 & 3,53 & 81,64 & 0,004 & 5,04 & 85,93 & 0,013 & 2,93 \\
\hline fenson & 97,4 & 0,0013 & 12,94 & 82,2 & 0,001 & 1,47 & 119,52 & 0,035 & 5,9 \\
\hline quinomethionate & 95,2 & 0,001 & 10,93 & 66,6 & 0 & 0,41 & 88,41 & 0,01 & 2,25 \\
\hline endrin & 81,2 & 0,0007 & 8,82 & 77,58 & 0,003 & 4,02 & 79,6 & 0,011 & 2,74 \\
\hline ethion & 89,6 & 0,0002 & 2,05 & 79,44 & 0,002 & 1,99 & 73,67 & 0,006 & 1,7 \\
\hline carbophenthion & 90,8 & 0,0004 & 4,55 & 73,32 & 0,003 & 3,89 & 77,08 & 0,027 & 7,1 \\
\hline endrin ketone & 96 & 0,0007 & 7,25 & 75,42 & 0,001 & 1,85 & 68,34 & 0,013 & 3,73 \\
\hline fenpropathrin & 74,8 & 0,0008 & 10,97 & 73,52 & 0,002 & 2,94 & 68,5 & 0,006 & 1,7 \\
\hline tetradifon & 131,2 & 0,0007 & 5,17 & 73,58 & 0,005 & 6,76 & 67,56 & 0,007 & 2,07 \\
\hline esfenvalerate isomer1 & 76,6 & 0,0003 & 4,14 & 72,06 & 0,009 & 11,82 & 72,8 & 0,013 & 3,51 \\
\hline esfenvalerate isomer 2 & 109,2 & 0,0007 & 6,06 & 64,16 & 0,002 & 3,76 & 59,93 & 0,006 & 2,02 \\
\hline esfenvalerate toplam & 92,9 & 0,0003 & 2,72 & 68,11 & 0,005 & 7,2 & 66,37 & 0,009 & 2,81 \\
\hline quintozene & 140,6 & 0,0003 & 2,04 & 97,32 & 0,002 & 2,4 & 104,1 & 0,017 & 3,26 \\
\hline bromophos ethyl & 125,4 & 0,0005 & 3,74 & 101,38 & 0,003 & 2,53 & 104,87 & 0,018 & 3,36 \\
\hline op DDD & 106,4 & 0,0003 & 2,91 & 102,2 & 0,002 & 2,27 & 105,24 & 0,018 & 3,46 \\
\hline pp DDD & 147,4 & 0,0003 & 2,24 & 96,36 & 0,002 & 2,39 & 105,81 & 0,017 & 3,25 \\
\hline nuarimol & 97,8 & 0,0005 & 5,6 & 104,44 & 0,003 & 2,46 & 103,53 & 0,016 & 3,15 \\
\hline chlorpyrifos methyl & 129 & 0,0011 & 8,72 & 104,22 & 0,005 & 4,39 & 103,54 & 0,01 & 1,86 \\
\hline op DDE & 112,8 & 0,0006 & 5,4 & 102,52 & 0,007 & 6,6 & 91,3 & 0,02 & 4,37 \\
\hline pp DDE & 118,2 & 0,0008 & 6,92 & 101,6 & 0,007 & 6,47 & 80,48 & 0,022 & 5,47 \\
\hline tetrasul & 66,8 & 0,001 & 14,72 & 84,86 & 0,008 & 9,2 & 76,41 & 0,02 & 5,31 \\
\hline
\end{tabular}

